\title{
Cancer-related trauma, stigma and growth: the 'lived' experience of head and neck cancer
}

J. THREADER, PHD, CANDIDATe, Research School of Psychology, Australian National University, Canberra, ACT \& L. McCORMACK, PHD, SENIOR LeCTURER/CliniCAl PSyChOlogist, Faculty of Science and IT, School of Psychology, University of Newcastle, Callaghan, NSW, Australia

\author{
THREADER J. \& McCORMACK L. (2015) European Journal of Cancer Care \\ Cancer-related trauma, stigma and growth: the 'lived' experience of head and neck cancer
}

Head and neck cancer is associated with multiple layers of distress including stigma. Stigma attraction or devalued social identity is twofold: (1) it is a cancer associated with lifestyle risk factors and (2) treatment often results in confronting facial disfigurement. Subjective interpretations from nine head and neck cancer patients were analysed using Interpretative Phenomenological Analysis. An overarching superordinate theme Distress, Stigma and Psychological Growth - encompassed four subordinate themes. Two themes captured the expressed trauma and terror as a result of diagnosis and treatment, and two the redefining of self despite stigma through meaning making. Distress was interpreted as a catalyst for awakening new life interpretations and combined with social support to facilitate two distinct pathways of growth: (1) psychological growth without support; (2) psychological and relational growth with support. Previously unfelt empathetic understanding and altruism for others with cancer emerged from the impact of stigma on 'self'. Acceptance allowed a new sense of identity that recognised cancer-related traumatic distress as integral to growth for these participants. The present study offers a unique insight into cancer-related trauma and stigma and the potential to redefine a more accepting, empathic and altruistic 'self' for psychological growth. Implications are discussed.

Keywords: IPA, stigma, cancer-related trauma, post-traumatic growth.

\section{INTRODUCTION}

Dealing with a cancer diagnosis and its associated treatments can be fear-provoking and life-altering. Many report helplessness and/or horror sensing that their life had been threatened as a result of their experience (Cordova et al. 2007). In addition to the terrifying shock at diagnosis, each cancer brings with it unique challenges to physical and psychosocial functioning (Stanton 2006). In particular, head and neck cancer patients may be at risk for increased distress (Frampton 2001; Zabora et al. 2001; Carlson et al.

Correspondence address: Lynne McCormack, Faculty of Science and IT, School of Psychology, University of Newcastle, Callaghan, NSW 2308, Australia (e-mail: lynne.mccormack@newcastle.edu.au).

Accepted 11 March 2015

DOI: $10.1111 /$ ecc. 12320

European Journal of Cancer Care, 2015
2004), as life-saving surgical intervention often leave them with significant and visually confronting changes to their facial appearance. Unfortunately, these physical changes may also impact on their functional ability to eat, swallow and speak, resulting in a reduced quality of life. Compounding the distress, disfigurement and disablement can attract unpredictable and even stigmatising responses from others (Macgregor 1990). Despite these known physical and psychosocial consequences, there is a paucity of research exploring the 'lived' experience of head and neck cancer. Therefore, this study will explore both positive and negative subjective interpretations of experiencing head and neck cancer. Through reflective semi-structured interviews, it seeks to understand how these participants have socially constructed, interpreted and made sense of: (1) being diagnosed with head and neck cancer; (2) disfiguring and invasive surgical intervention; and (3) social support and societal responses to this type of cancer. 
Stigma refers to an attribute, visible or non-visible, that identifies the individual as being part of a social category that is undesirable (Jones et al. 1984). The bearer of stigma becomes segregated, 'devalued' and 'discredited' (Goffman 1963, p. 3). For those struggling with the aftermath of a cancer diagnosis, cancer-related stigma increases illness burden and can lead to physical, social and psychological morbidity (Peters-Golden 1982; Gamba et al. 1992; Fife \& Wright 2000). For example, stigma can result in reduced self-esteem (Fife \& Wright 2000), is likely to increase isolation and strain social relationships (Peters-Golden 1982), and lead to delayed symptom reporting (Tod et al. 2008). These consequences do not independently impact on cancer patients; they are likely to be multifaceted, inter-related and exacerbate each other. Furthermore, given positive social support has been found to assist in helpful coping and recovery in chronic illness (Suls 1982), the effects of stigma pose challenges to a cancer patient's self-concept and recovery.

There are several stigmatising factors that uniquely impact on the aftermath of head and neck cancers. For instance, as the facial region is an important aspect of an individual's identity, changes to facial appearance often cause extreme distress and embarrassment (Macgregor 1990; Fingeret et al. 2012). Consequently, body image concerns are highly prevalent among head and neck cancer patients (Fingeret et al. 2012). Furthermore, facial disfigurement may impact on an individual's sense of self (Callahan 2005) and well-being (Dropkin 1999) as a visible stigma ' ... can provide the primary schema through which everything about them is understood' (Crocker et al. 1998 , p. 507). In fact, facial surgery associated with head and neck cancer has been described as a destruction of self (Turpin et al. 2009).

Head and neck cancer has been described as one of the most emotionally traumatic types of cancer (Breitbart \& Holland 1988; Dropkin 1989). Those with head and neck cancer face a 'dual burden'; in addition to adjusting to the physical change and debilitation following treatment, treatment itself for head and neck cancer can be particularly distressing, as it has been associated with increased anxiety and significant pain (Dropkin et al. 1983; Dropkin 2001). These negative effects can lead to physical and psychosocial impairment. Physically, treatment can cause extreme pain and dryness in mouth and neck areas, impacting on difficulties eating and drinking. Consequently, recovery can be long, resulting in delayed return to work, limited ability to engage in social activities and isolation (Krouse et al. 1989). For many, resultant functional debilitations may further exacerbate and prolong psychosocial difficulties by impairing communication, interfering with social interactions and relationships (Koster \& Bergsma 1990) resulting in feelings of isolation and restricting social activities (Gamba et al. 1992). Sadly, stigma associated with facial disablement and disfigurement following surgery can add to that emotional distress, impacting on reduced self-esteem, social anxiety, self-consciousness, depression and quality of life (Krouse et al. 1989; Devins et al. 1994; Clarke 1999).

Beliefs about personal behaviours associated with certain cancers may also impact on feelings of stigmatisation, the trajectory of recovery and sense of self. Lifestyle risk factors associated with head and neck cancers, including alcohol and tobacco consumption (Castellsagué et al. 2004), and human papilloma virus (HPV) infection (Herrero et al. 2003), can attract blame and stigma. Yet, research investigating stigma associated with perceived onset controllability among head and neck cancer is very limited (Lebel \& Devins 2008). However, there is a growing research base documenting the stigmatisation associated with smoking and lung cancer. Several research studies have reported that lung cancer patients are more stigmatised than individuals diagnosed with other cancer types, because lung cancer is perceived to be a self-inflicted disease (Chapple et al. 2004). Among lung cancer patients, this stigma has been found to lead to delayed symptom reporting and increased distress (Raleigh 2010) including feelings of guilt and depression (Kuo \& Ma 2002). Behavioural risk factors associated with head and neck cancer, such as alcohol consumption and smoking cigarettes, can elicit blameworthy attributions. As a result, patients are at risk of encountering stigmatising attitudes. Therefore, patients with head and neck cancer are at risk of psychological distress due to both the impact of the cancer diagnosis and its associated stigmatising reactions.

While distress has been associated with poorer functioning (Hegel et al. 2008), a growing body of research has documented that it can be the catalyst for psychological growth and personal development and helps explain why some individuals achieve increased psychological wellbeing after a traumatic event (Joseph \& Linley 2005; Joseph 2011; Joseph et al. 2012). These individuals find meaning from the event and accommodate trauma-related material in a way that strengthens personal, philosophical and relationship values (Joseph 2011). Understanding how individuals find meaning and develop positive change following cancer diagnosis and treatment is important, given post-traumatic growth has been associated with increased quality of life and protection from depression among breast cancer survivors (Morrill et al. 2008).

While post-traumatic growth theory highlights the critical role of positive social support (Ryff 1989; Tedeschi \& 
Calhoun 1995; Joseph \& Linley 2005), recent research suggests that an individual's intrinsic drive to make meaning of distressing events may facilitate a positive redefining of self over time irrespective of positive, and despite negative, external support (McCormack \& Joseph 2014). Similarly, a small but burgeoning literature suggests that positive outcomes can occur despite the stigma experienced by head and neck cancer patients (Ruf et al. 2009; Thambyrajah et al. 2010; Llewellyn et al. 2013). In fact, early findings suggest that post-traumatic growth can lessen the negative effect of cancer stigma on psychosocial outcomes (Lebel et al. 2013a).

Several aspects of journeying with head and neck cancer are poorly explored. The role of positive social support for psychological growth is posited as necessary (Joseph 2011) suggesting growth is unachievable post-trauma without positive support. Recent studies, however, suggest that growth is possible without support, though delayed (McCormack \& Joseph 2013, 2014). Several studies have posited that the relationship between post-traumatic distress and growth following trauma is curvilinear with a critical point for cognitive processing (Butler et al., 2005). Purposeful rumination is said to be the central tenet to that curvilinear relationship and is therefore regarded as key to growth following trauma (Calhoun \& Tedesch, 1999; Nolen-Hoeksema \& Davis, 2004). How social support impacts on that central tenet is currently unknown.

Similarly, distress, stigma (Peters-Golden 1982; Gamba et al. 1992; Fife \& Wright 2000) and post-traumatic growth (Lebel, 2013b) are recognised individually in the cancer literature, but little is known regarding subjective interpretations of the co-experience of all three among those who have experienced head and neck cancer. Therefore, using Interpretative Phenomenological Analysis (IPA; Smith 1996), this study aims to add to the extant literature by exploring both positive and negative subjective interpretations of experiencing head and neck cancer. In particularly, it seeks to understand how these participants have socially constructed, interpreted and made sense of: (1) being diagnosed with head and neck cancer, (2) experiencing invasive surgical intervention; and (3) social support and societal responses to this type of cancer.

\section{METHOD}

\section{Participants}

Nine participants, eight male and one female, with a history of head and neck cancer were recruited through nursing referral at a leading teaching hospital in Australia. Participants were eligible if they had been surgically treated for head and neck cancer, which had resulted in changes to their facial appearance. This was assessed by the Cancer Nurse Coordinator who had many years of experience working with individuals diagnosed and treated for head and neck cancer. All participants had been treated with a neck dissection to remove cancerous areas. Table 1 outlines demographic characteristics of each participant. Pseudonyms are used to protect confidentiality.

\section{Procedure}

Following human ethical clearance, participants were sourced through referral from head and neck cancer nurse coordinators, who had been briefed about the project and provided with information regarding eligibility criteria for the study. Participants were subsequently contacted by telephone with information about the study. Study materials including the participant information form, consent form and outline of the semi-structured interview were sent to participants prior to the interview, to help ensure that participants were fully aware of the study's purpose and the material to be covered (Smith et al. 2009). The one-on-one interviews were conducted at a time and location most convenient for both parties.

All interviews were audio-recorded using a digital voice recorder and ranged in duration from 40 to $93 \mathrm{~min}$. Participants received a \$25(AUD) gift voucher. The interviews were guided by semi-structured questions, which 'funnelled down' interview material to the topic of interest (Smith \& Osborn 2008). The flexible nature of the interviews allowed participants to engage in the double hermeneutics of the dialogue freely and openly, exposing the phenomenon of study interest.

\section{Epistemology}

The philosophical underpinnings of the present study rely on phenomenology, critical realism and symbolic interactionism (Denzin 1995). Therefore, it aimed to describe the way in which each participant's world was constructed, interpreted and understood (Spinelli 2005) by allowing the participants to reflectively interpret the immensurable realities of their experience of head and neck cancer (Blaikie 1991). As symbolic interactionism (Blumer, 1969) is the process of interaction in the formation of meanings for individuals, phenomenological studies offer the opportunity for researchers and participants to understand how individuals are influenced by their social interaction, and by the dynamic nature of meaning, which is modified through their interpretation. As the participant's world is always dependent on interpretation of their environment the meaning participants of 
Table 1. Participant characteristics

\begin{tabular}{|c|c|c|c|c|c|c|c|}
\hline & Age & Gender & $\begin{array}{l}\text { Time between } \\
\text { surgery and } \\
\text { interview } \\
\text { (approx.) }\end{array}$ & $\begin{array}{l}\text { Specific Head and } \\
\text { Neck cancer }\end{array}$ & Onset information & Stage & Other treatments \\
\hline 'James' & 72 & M & 9 months & $\begin{array}{l}\text { Squamous cell carcinoma - } \\
\text { floor of mouth }\end{array}$ & $\begin{array}{l}\text { Non-viral - participant } \\
\text { attributes to smoking }\end{array}$ & T4NOMO & Radiotherapy \\
\hline 'Matt' & 57 & M & $\begin{array}{l}1 \text { year, } \\
2 \text { months }\end{array}$ & $\begin{array}{l}\text { Squamous cell carcinoma - } \\
\text { of tongue base }\end{array}$ & $\begin{array}{l}\text { Viral (p16 positive) - } \\
\text { participant attributes } \\
\text { to HPV }\end{array}$ & T2N2aM0 & $\begin{array}{l}\text { Radiotherapy and } \\
\text { chemotherapy }\end{array}$ \\
\hline 'Felix' & 42 & M & 10 months & $\begin{array}{l}\text { Squamous cell carcinoma - } \\
\text { floor of mouth }\end{array}$ & $\begin{array}{l}\text { Non-viral - participant } \\
\text { attributes to smoking }\end{array}$ & T2N0M0 & $\begin{array}{l}\text { Radiotherapy and } \\
\text { chemotherapy }\end{array}$ \\
\hline 'Derek' & 36 & M & $\begin{array}{l}1 \text { year, } \\
2 \text { months }\end{array}$ & $\begin{array}{l}\text { Basaloid squamous cell } \\
\text { carcinoma - right mandible }\end{array}$ & $\begin{array}{l}\text { Viral (p16 positive) - } \\
\text { participant attributes } \\
\text { to HPV }\end{array}$ & T0T2bMx & $\begin{array}{l}\text { Radiotherapy, } \\
\text { incomplete } \\
\text { chemotherapy }\end{array}$ \\
\hline 'Ralph' & 56 & M & 1 month & $\begin{array}{l}\text { Squamous cell carcinoma - } \\
\text { right neck }\end{array}$ & Non-viral & TxN2Mx & $\begin{array}{c}\text { Radiotherapy and } \\
\text { chemotherapy }\end{array}$ \\
\hline 'Paul' & 58 & M & 2 months & $\begin{array}{l}\text { Squamous cell carcinoma - } \\
\text { lateral tongue }\end{array}$ & Non-viral & $\mathrm{T} 1 \mathrm{~N} 1 \mathrm{Mx}$ & $\begin{array}{l}\text { Radiotherapy and } \\
\text { chemotherapy }\end{array}$ \\
\hline
\end{tabular}

F, female; M, male.

this study ascribed to their experience with head and neck cancer were influenced by the subjective meaning participants brought to them. Relatedly, a critical realist perspective embraces hermeneutic exploration where individuals are constantly finding meaning and interpreting their environment to inform their behaviours (Gadamer 1983). This methodological approach highlights the multiple ways in which an experience can be construed, and moves beyond the discord between objectivism and relativism paradigms (Bernstein 1983). These interpretations fit with both the objectivism stance, which argues that there is only a single valid perspective for meaning making, and the relativism perspective, which contends that there is no absolute truth and that perspectives vary by individual. Through this lens, the study used IPA to analyse the data.

\section{Analysis}

Data were collected by use of an audio recording device. Interviews were transcribed verbatim by the first author. Following steps outlined by Smith et al. (2009), first, each author independently read and re-read the transcripts, with initial note taking made on the left-hand side; specific font style denoted descriptive, linguistic and conceptual content. Second, material was reviewed independently, incorporating psychological theories and abstractions. These specific themes and short phrases were placed on the right-hand side of the transcript. Third, each author collated emergent themes that began to develop by identifying the inter-connections and patterns in the exploratory notes. When the procedure was complete for each transcript, the two authors met for robust discussion to agree on convergent and divergent themes. The process was repeated for each transcript. The final stage included developing higher order themes and subthemes across the data set. A step-by-step analysis of the analytic process is provided in Table 2 .

\section{Credibility}

Rather than provide evidence for inter-reliability and causal relationships often found in quantitative research, the current research employed a detailed audit trail for data review (Smith et al. 2009). That is, the audit sought to provide the reader with an account of the data that was analysed in a systematic manner. Data achieved internal coherence, credibility and interpretive rigour, through this detailed audit trail (i.e. raw data, transcripts, notes, diagrams) with robust discussions checking for biases and presuppositions at every level (Smith \& Osborn 2008).

The first author conducted and transcribed each of the interviews verbatim. Both authors conducted completely independent analyses of the transcripts. Authors met to review independently reviewed transcripts, during which common themes were checked for authenticity, and inde- 
Table 2. Outline of the stages involved in the Interpretative Phenomenological Analysis

\begin{tabular}{|c|c|}
\hline Stage & Process \\
\hline 1 & Re-listening, verbatim transcription, preparation of first transcript \\
\hline 2 & $\begin{array}{l}\text { Independent first interpretation by both authors - noting, paraphrasing and summarising the participant's experience; } \\
\text { development of emerging themes }\end{array}$ \\
\hline 4 & $\begin{array}{l}\text { Stages } 1-3 \text { repeated for eight additional transcripts - identifying convergence and divergence across cases. Clustering } \\
\text { of themes that support evidence of subordinate theme }\end{array}$ \\
\hline 7 & $\begin{array}{l}\text { Continued assessment of themes and subthemes, including how they related and linked to meaning making, redefining } \\
\text { self and well-being }\end{array}$ \\
\hline 8 & Clustering of themes in relation to constructs and theories \\
\hline 9 & Data from transcripts reviewed by authors to verify the validity of interpretations from within the text \\
\hline 10 & Central theme of 'Distress, Stigma and Psychological Growth' re-assessed \\
\hline 11 & $\begin{array}{l}\text { Subjective analysis of interpretations for themes representing the phenomenon of the lived experience of head and neck } \\
\text { cancer within the context of distress and stigma to develop pathways to personal and relationship growth and well-being }\end{array}$ \\
\hline
\end{tabular}

pendent interpretations were reflected on and robustly debated (Smith et al. 2002). Throughout, subsequent communication, reflection of the reiterative and interpretive process and rigorous discussion between authors established a thematic framework supported by rich extracts from the data. A table of convergent and divergent higher order and subthemes was subsequently developed (see Table 3).

\section{Author's perspective}

Interpretative Phenomenological Analysis, which involves double hermeneutics, is influenced by the researchers own experiences and preconceptions (Smith 1996). In essence, it is a process of reiterative sense making where the researchers strive to make sense of the participant making sense of their experiences. Through an iterative process, the relationship between each researcher and script was considered to reduce biases, and prevent a major shift in interpretation from the participant's experience and world view to the researchers. Without this, there is the risk that preconceptions and interpretation will be moulded by our own human experience (Heidegger, 1927/1962). Previous experience and knowledge about psycho-oncology and post-trauma reactions challenged the authors to reflect and recognise their own biases and

Table 3. Superordinate theme: distress, stigma and psychological growth overarching subordinate themes

1. Head and neck cancer: trauma trajectory

2. THIS cancer: stigma and distress

3. Looking beyond the previous self

4. Positive change - self presuppositions that may have impacted on the interpretation of the data. In the present study, we sought to externalise these preconceptions through reflective practices, independent audit, audit trails and ongoing discussion throughout the analysis.

\section{RESULTS}

The following results include the study's thematic outcomes, presented in narrative descriptive analysis. An overarching theme - Distress, Stigma and Psychological Growth - encompassed four superordinate themes: (1) Head and neck cancer: trauma trajectory; (2) THIS cancer: stigma and distress; (3) Looking beyond the previous self; and (4) Positive change - self. Two of these themes captured the expressed trauma and terror as a result of diagnosis and treatment whereas themes 3 and 4 captured the redefining of self despite stigma through meaning making. Distress was interpreted as a catalyst for awakening new life interpretations and combined with social support to facilitate two distinct pathways of growth: (1) psychological growth without support; (2) psychological and relational growth with support. Previously unfelt empathetic understanding and altruism for others with cancer emerged from the impact of stigma on 'self'. Acceptance allowed a new sense of identity that recognised cancerrelated traumatic distress as integral to growth for these participants. The present study offers a unique insight into cancer-related trauma and stigma and the potential to redefine a more accepting, empathic and altruistic 'self' for psychological growth. The quotations were not chosen based on prevalence within the data, rather they reflect rich evidence from the transcripts. 


\section{Head and neck cancer: trauma trajectory}

Compounding trauma

This theme captures the intensity and multiple layers of distress through diagnosis, treatment and recovery faced by head and neck cancer patients. The fast pace at which they were thrust into an unfamiliar medical system made them feel caught off-guard and vulnerable:

It's extremely confronting ... when you can get into a specialist in 4 hours, you then know you are in trouble. [Matt]

While at the same time, attempts at mentally preparing seemed futile. They were never going to be ready for the journey ahead of them:

It all happened at once. And that was so much to take in ... if I only had a few more months, I'd be prepared but I guess you're never really prepared. [Derek]

Distressing procedures and lengthy recovery times overwhelmed their coping abilities. Cognitive blocking was used as a means to escape and avoid intrusive images associated with losing functional ability to speak and eat, a significant impairment to quality of life:

[With] surgery you could lose ... all of your tongue

... [it] really messes with your head... you're trying

to think that one through. [Matt]

Intense feelings of anxiety during the procedures imprinted indelible vivid memories on their consciousness. This meant that physical manifestations of emotional responses to the multiple distressing and traumatic events often unexpectedly overwhelmed them:

I got started again; a few weeks between surgery and radiation ... lots of anxiety ... I was having panic attacks. [Derek]

\section{Terror of collaboration}

Although adverse events often occur unexpectedly, medical procedures have their own way of inflicting trauma through complicit consent to the fearful physical invasion of their body. These participants spoke of their panic, horror and fear dealing with the tracheotomy tube. Unable to breathe, handing trust to staff during suctioning of their airway, they felt they had been taken to the brink of life or death:

Absolute panic mode ... I didn't know that they'd suction out my throat and lungs, that I would have a tube poked down there regularly to suction out the phlegm. You feel like you are choking... the sheer terror. [Felix]

Other highly invasive treatment compounded their distress. The participants spoke of the refinement of medical tools as a symbolic representation of the seriousness of their cancer and the fragility of their life:

At each of these steps you sort of realise that you are getting progressively more seriously into the system and down in terms of ah the subtlety of the tools that are being used. [Paul]

Their memories of the event were vivid and extremely distressing. The removal of the tracheostomy tube was a symbol of being handed back control over life. It was a major hurdle and a symbol of recovery.

That was a new lease on life, taking the trachy out - cause that was probably the worst week of my life. [Derek]

'Why me?' versus 'This is it'

'Why me?' was commonly asked for sense making of distressing experiences, particularly among those participants whose lifestyle was healthy prior to diagnosis with cancer. They spoke of feeling punished and undeserving of this fateful narrative:

It was a bit of a shock. Why? I had a healthy lifestyle, why me? ...you do the right thing and you're still punished. [Derek]

Feelings of disconnectedness, a mind struggling to accept a body needing medical intervention, these participants described experiencing shock and disbelief:

I never expected it to happen to me so in some ways it's this out of body experience going on here. [Paul]

However, for older participants there was acceptance, even embracement, of a diagnosis that aligned appropriately with their narrative of life. The three eldest participants, James, Shannon and Kevin recognised the journey they had lived as a long and valuable life, and welcomed cancer as part of their mortality:

Before I went into hospital, I didn't really know whether I would be coming out. And I didn't really ask, but I suppose - I think I would accept what has happened to me. [James] 
Some found their own acceptance of cancer was at odds with others' desire to extend their lives. If death was inevitable, they had no desire to extend life:

Once you get to 83 you have had a good life. All I could think at the time was if it is going to happen let it be quick. Don't linger on. [Shannon]

\section{Confronting the unimaginable}

Multiple distressing procedures brought raw trauma that overwhelmed all participants. Pragmatic coping statements seemed relevant for distancing anxiety, fear and terror. It was a stopgap that allowed time for more purposeful rumination and reframing:

You are going to treat it as a job ... a really shitty job to do ... we kept on going back to that ... when, you know, we were getting sort of those dark days. [Matt]

Each imagined that other cancer patients were experiencing greater suffering. This allowed distance and a level of detachment from personal multiple and ongoing traumatic experiences:

And you know, I mean there is always someone worse off, as bad as you think things are someone is getting it worse. Yah? It makes you think, all these little things. [Derek]

Having difficulty confronting the unimaginable, some participants required the assistance of a support partner to guide them through their journey. These partners became intimately involved in their experience, to be their eyes and ears to absorb information:

At the bed day-by-day, and having to watch me go through... the nightmare of surgery ... being able to talk to her about it afterwards, debrief. [Felix]

These participants described a dual conflict of sense making. First, their personal narrative of consensual trauma, along with the pain and acceptance of permanent disablement challenged their world view of themselves. Second, unexpected responses from others ingeminated the degree to which their physical identity had changed. Witnessing visible shock in others was an added burden to their unwelcomed relationship with cancer. It was as if mortality was reflected back through the expressions of others:

People's reaction ... was confronting ... you could see it in their face, their facial reactions. Like a deer in the headlights ... the word cancer, they think you are going to die. [Derek]

\section{THIS cancer: stigma and distress}

Identity struggle

Cumulative upon the fearful experience of undergoing invasive medical procedures, participants were challenged with the permanent aftermath of changes to their facial appearance. Physically, as head and neck cancer participants they became unrecognisable from a previous 'self'. This traumatic journey felt unending as adjusting to a new physical 'self' confronted their sense of former sense:

I wasn't recognised by a very close friend... quite a few actually... that was a bit of a shock. [Derek]

The impact of physical changes was juxtaposed with changes to their personality. Struggling with a dichotomous identity, they had to re-evaluate and redefine who am I. Embarrassed to engage in once common social experiences they recognised a tendency to isolate themselves more than ever:

I feel a bit shut in... I don't want to go out ... if there is a barbeque on I won't go. It is just too hard to constantly explain... why I have got the scars. [Felix]

While medical treatment left these participants physically exhausted, confronting others' furtive stares and learning how to cope with stigmatising reactions took its toll emotionally. Grief and loss persisted throughout the interviews as these participants struggled to reconcile visual changes. Coming to terms with their new appearance was a twisting game of disappointments and lost identity:

The physical, the weight ...were negative impacts ... it still hurts, it really hurts actually, that's what upset me the most. ... I just didn't feel myself. [Derek]

\section{Change to self: a need to belong}

While no longer feeling part of their once extended social circles, a sense of inclusion grew among other stigmatised groups. Comfort was experienced, from a shared sense of understanding and struggle to belong again:

Other people with disfigurement or disablement don't even look at me... will give me a nod and that's it. So that's kind of the style of brotherhood or sisterhood ... because they go through the same stigmatism. [Felix] 
Close friends and family were seen as integral to adjusting to new 'self'. Looking past the physicality they were able to buffer situations, which enabled processing. By interacting in a way that was consistent with their previous 'self', a slow transition to a new 'self' occured:

The ones that treat me the same, which I appreciated more because ... they just didn't treat me like I was wrapped in cotton wool, didn't baby me. And that's all you wanted to be, is treated as you were. [Derek]

\section{A deviant past}

In addition to the physical stigmatising changes, head and neck cancer patients are confronted with personal lifestyle factors (i.e. alcohol, smoking and HPV infection), which may have made them vulnerable to developing this cancer in the first place. Participants who attributed their cancer onset to past behaviour were regretful of their past and bitter about the consequences.

It's my own stupid fault. I smoked for 28 years ... smoking causes my cancer' [Felix]

Secrecy and invisibility were maintained by many as if holding onto a deep regret about their role in developing cancer. Privately, they acknowledged their own contribution to developing this feared illness, often perceived to develop by unlucky chance. However, fear of rejection and abandonment struggled with feelings of self-blame and guilt:

I suppose sexually transmitted infections, or diseases, that's something we left out quite a lot...there is such a stigma attached. [Derek]

They sensed a wide-spread stigma associated with a blameworthy cancer. For some, self blame was expressed as underserving of the level of compassion afforded other cancers. Feeling shunned they sensed a general lack of support was associated with stigma. Quietly, they felt anger and a sense of injustice:

There is just no information available no level of support for us at all...because its head and neck cancer, it's not popular... because its smoking related... it's not a poster-boy cancer. [Felix]

\section{Looking beyond previous self}

\section{Awakenings}

Confronting the possibility of an early death, there were moments that could be described as awakenings for these participants. Their future was now on a different and unfamiliar journey:

You've sort of confronting something that's released a lot of um... inhibition or things you'd always sort of and grown up and been part of you. [Matt]

Uncertainty about the future and fragility of life brought a focus to what is most important to them. This was experienced differently for participants whether they had approached their journey with independence and stoicism, or had become vulnerable and reliant on their family. While the former had developed a sense of focusing on personal insight and growth:

It's a wakeup call that you're not going to live forever. I have a long list of things of things I want to do... that was always vaguely in the future but I'm thinking now I should just do them. [Paul]

The latter had become more engaged in building stronger meaningful relationships:

This focuses the mind more, at looking at things you value more in life ... like your family and relationships... you've only got them for a finite time so you should make the most interactions with them. [Ralph]

Those, however, who had accepted cancer as a part of their narrative in life, had embraced these changes and came to a humbled understanding of their place and impact in the world.

It's one day at a time, I can't alter the world now. [Shannon]

\section{Positive change - self \\ Empathetic understanding}

In the struggle to understand new 'self', a greater sense of compassion emerged in the participants. Personal adversities and an empathic understanding of others was described, enabling these participants to communicate more effectively and meaningfully. Their journey with cancer brought unexpected positive changes to their life perspectives and an openness not previously experienced in their close relationships:

I have become close to them...I find it easier to talk to them [his children]. Not that it was hard, but... in a different style. You know? [Matt]

These participants expressed a change in interpretation of life from their struggle with 'self' on this journey. 
Experiencing unexpected stigma despite their personal suffering, they began to find a new acceptance of others. Redefining self through a stigmatising cancer became the catalyst for increased understanding and a new insider's perspective:

I now see people with either, illnesses or disabilities and I'm a lot more understanding of what they are ... until you go through it - I don't think you sort of appreciate. [Matt]

\section{Altruism}

The uniqueness of the head and neck cancer journey and the invasive procedures that terrorised the patients, paradoxically facilitated a desire to help others. Consciously, their personal experience of stigma while at their most vulnerable appeared to facilitate a growth in altruism. Defining a new altruistic identity became a vehicle for personal acceptance allowing others in turn to accept:

This cancer, you can't hide it, you can't sort of put a great big hat on or cover half your face ...where many other cancers you wouldn't know, you don't have the visual impact...so in one way, it helps you to help other people too. [Kevin]

Having positive support from a partner appeared interwoven with this increased desire to help others. As vanguards, these supportive loved appeared to enable participants to re-integrate into society:

I often wonder what would happen if I was here by myself and [my wife] wasn't here; how different it would have been... because I would then, by nature would have hidden away. [Kevin]

Endurance was made more possible through positive partner support allowing empathy and support of others to be projected forward. Passing on optimism to others starting the journey with head and neck cancer became important. Head and neck cancer was perceived as bringing both positive and negative outcomes inclusive of psychological well-being and a new purpose in life:

I am going to share it [my experience] with people... if what I've got can help people, then I am very happy. [Matt]

\section{DISCUSSION}

This study highlighted cancer-related traumatic distress and stigma in these participants as a result of dealing with head and neck cancer. However, despite this distress, positive changes emerged from finding meaning of the stigma and traumatic distress. The participants expressed experiencing trauma and terror as a result of diagnosis and treatment, and unexpected stigma from society as a result of their particular cancer. Over time however, distress became a catalyst for awakening new life interpretations and psychological growth to varying degrees with these participants. Sometimes, this occurred with positive social support and sometimes without support. When support was present, relational growth appeared to be experienced. For all participants, previously unfelt empathetic understanding and altruism for others with cancer emerged from the impact of stigma on 'self'. Similarly, acceptance allowed psychological well-being to emerge out of their experience with cancer-related traumatic distress.

The present study offers a unique insight into cancerrelated trauma and stigma and the potential to redefine a more accepting, empathic and altruistic 'self' for psychological growth. By shedding light on the relatively unexplored influence of stigma on psychological growth, within a relevant and understudied population, the current findings can be used to inform hypotheses for future idiographic and nomothetic research. Implications are discussed.

For these participants, psychological growth was experienced differently, depending on social support. Psychological growth was reported among participants without social support; on the other hand, psychological and relationship growth was described among those with social support. Importantly, with or without support, these participants experienced positive change as a result of their exposure to cancer-related trauma and stigma which supports earlier studies recognising that with or without support, post-traumatic growth can occur (McCormack et al. 2011; McCormack \& Joseph 2013, 2014).

Psychological growth was described among individuals who had approached their cancer journey with independence and stoicism. This domain of post-traumatic growth is defined as becoming more compassionate, gaining wisdom and discovering inner strength (Joseph 2011). For participants in the present study, psychological growth developed as a result of finding inner strength in the face of cancer-related distress and stigma, by redefining their lives through purposeful reflection and engaging in valued activities and experiences. Participants found meaning from their lone journey by creating a new personal narrative. While social support has been found to increase positive adjustment with chronic illness (Suls 1982), here, independence and the need to rely on their own abilities and inner strength to cope led to increased confidence. This new found sense of strength and wisdom was a turn- 
ing point, facilitating personal growth. The current findings support previous qualitative (McCormack \& Joseph 2014) and quantitative (Widows et al. 2000; Weiss 2004) research which found that post-traumatic growth is not dependent on social support. Indeed, individuals are innately driven towards growth, in the pursuit of increased well-being (Joseph \& Linley 2005). In the present study, developing their sense of self and actively taking time to live out their own dreams, such as accomplishing their 'bucket list', was put at the forefront of their priorities to improve greater life satisfaction and fulfilment. Relying on themselves through their journey offered a period of self-discovery, where participants' increased their own psychological well-being through self-acceptance, inner strength, autonomy and redefining their purpose in life.

Participants who had become dependent on family for support additionally reported increased growth in their relationships. This was represented by an increased appreciation for significant others. Meaning making from their cancer experience and distress was found to develop from their social support. On their journey, support partners were able to facilitate the participants' needs, aiding them in treatment and recovery. While most core beliefs about themselves and the world had been disrupted as a result of cancer (Holland \& Reznik 2005), the availability of positive social support validated that they were loved and cared for, enabling them to find meaning (Silver \& Wortman 1980). As such, their distressing experiences had been interpreted as a catalyst for illuminating their important relational bonds. Participants identified they had changed their lives by making more time for loved ones, valuing and appreciating that time, thereby improving the quality of interactions with them. Therefore, the cancer journey brought with it a realisation that life is finite, and redefined purpose in life by strengthening relationships.

While cancer diagnosis and treatments was distressing, which increased awareness of what is important in life, head and neck treatment brought with it stigmatisation that also increased distress. For example, facial changes following surgery resulted in a visible stigma that was not able to be concealed. As one participant noted: 'this cancer, you can't hide it, you can't sort of put a great big hat on or cover half your face'. The visibility of their facial changes made participants vulnerable to stigmatising reactions from others. These responses became internalised, impacting on their self-concept (Livingston \& Boyd 2010). The present results highlighted the persistent and intense feelings of grief, loss and ongoing distress regarding the visual changes.
Prior research reporting the distressing and deleterious effects of facial disfigurement, including stigmatising responses from the public (Hagedoorn \& Molleman 2006), strained social relationships and subsequent social isolation (Myers et al. 1999), is supported in the present results. Consequently, participants reported significant distress in regards to their facial changes, and struggled to redefine who they were. What these participants uniquely experienced was that through active self-discovery and self-acceptance, they were able to move towards positive transformation. Cognitive processing involved making meaning from the societal stigmatisation and forced new identity through the development of a personal narrative. As a result of their traumatic and stigmatising head and neck cancer journey, and their struggle through this experience, growth was seen in increased altruism and empathetic understanding. While these post-traumatic growth domains are not currently captured in measures assessing psychological growth, the phenomenological interpretation of these findings supports previous qualitative research, which has also documented these domains of growth (McCormack \& Joseph 2014).

The results suggest that by finding meaning from the stigma, participants had developed a new sense of purpose in life to help and understand others. The capacity to see beyond their physical identity lead to a sense of self-acceptance. In turn, participants felt more accepted by others. Consequently, participants found new meaning in their lives, by self and other acceptance and personal growth through self-discovery. Therefore, while stigmatisation can lead to discrimination and prejudice, reducing quality of life (Fingeret et al. 2012), straining social relationships (Macgregor 1990), the present findings highlight that this distress can facilitate personal meaning making and psychological growth.

\section{LIMITATIONS}

The present findings should be considered in the light of study limitations. Using an interpretative approach, results are open to the subjective biases as a result of the researchers own self-world, encompassing personal experiences and understandings. However, study methodologies were employed to illuminate biases and presuppositions, which involved completely independent audits and robust discussion.

While quantitative research strives to recruit a sample which would allow for generalisability of results, qualitative research, and IPA in particular, seeks a homogenous cohort for in-depth, subjective exploration by individuals who have experienced a unique phenomenon previously 
unexplored. The current findings contribute to the literature on distress, growth and stigma, and provide direction for future qualitative and quantitative research.

\section{CONCLUSIONS}

These findings provide further insight into cancer-related traumatic distress and stigma, uniquely specific to head and neck cancer. Similar to earlier studies, the participants felt stigmatised adding to their burden of trauma, fear and loss of self-esteem (Peters-Golden 1982; Gamba et al. 1992; Fife \& Wright 2000). Socially they felt ostracised, isolated and struggled to recognise supportive social relationships (Peters-Golden 1982). When positive support was forthcoming, they honoured it as helping them to cope with the difficult challenges of this protracted journey (Suls 1982).

These participants' traumatic responses mirrored the dual burden of physical debilitation and fear of treatment described in other studies (Breitbart \& Holland 1988; Dropkin 1989). They similarly described the distress asso- ciated with medical procedures and the ongoing psychosocial impact of other stigmatising factors relevant to the head and neck cancer experience.

Importantly, this study raises awareness that psychological growth is possible from the stigmatising and complex physical and psychological journey with head and neck cancer. For these participants, a positive redefinition of self, evolved over time and was enhanced by positive support. Similarly, these findings offer hope to health care professionals that positive psychological growth is possible despite cancer-related trauma and stigma associated with head and neck cancer and with facial changes following surgery. As a qualitative study, it offers hypotheses for future nomothetic research. Nonetheless, in a therapeutic framework this study emphasises the importance of providing space for head and neck patients to elicit a narrative that explores the likelihood that trauma psychopathology and growth may co-exist. Equally, therapeutic intervention can provide a positive framework for growth out of traumatic distress.

\section{REFERENCES}

Bernstein R.J. (1983) Beyond Objectivism and Relativism: Science, Hermeneutics, and Praxis. University of Pennsylvania Press, Philadelphia, PA, USA.

Blaikie N.W. (1991) A critique of the use of triangulation in social research. Quality and Quantity 25, 115-136.

Breitbart W. \& Holland J. (1988) Psychosocial aspects of head and neck cancer. Seminars in Oncology 15, 61-69.

Blumer H. (1969) Symbolic interactionism. Prentice Hall, Englewood Cliffs, NJ.

Butler L.D., Blasey C.M., Garlan R.W., McCaslin S.E., Azarow J., Chen X.-H., Desjardins J.C., DiMiceli S., Seagraves D.A., Hastings T.A., Kraemer H.C. \& Spiegel D. (2005) Posttraumatic growth following the terrorist attacks of September 11th 2001: Cognitive coping and trauma symptom predictors in an internet convenience sample. Traumatology 11, 247-267.

Calhoun L.G. \& Tedeschi R.G. (1999) Facilitating Posttraumatic Growth: A Clinician's Guide. Lawrence Erlbaum, Mahwah, NJ.

Callahan C. (2005) Facial disfigurement and sense of self in head and neck cancer. Social Work in Health Care 40, 73-87. doi:10.1300/J010v40n02_05.

Carlson L.E., Angen M., Cullum J., Goodey E., Koopmans J., Lamont L., MacRae J.H., Martin M., Pelletier G., Robinson J., Simpson J.S.A., Speca M., Tillotson L. \& Bultz B.D. (2004) High levels of untreated distress and fatigue in cancer patients. British Journal of Cancer 90, 2297-2304. doi:10.1038/ sj.bjc. 6601887.

Castellsagué X., Quintana M.J., Martínez M.C., Nieto A., Sánchez M.J., Juan A., Monner A., Carrera M., Agudo A., Quer M., Muñoz N., Herrero R., Franceschi S. \& Bosch F.X. (2004) The role of type of tobacco and type of alcoholic beverage in oral carcinogenesis. International Journal of Cancer 108, 741-749. doi:10.1002/ijc.11627.

Chapple A., Ziebland S. \& McPherson A. (2004) Stigma, shame, and blame experienced by patients with lung cancer: qualitative study. British Medical Journal 328, 1470. doi:10.1136/ bmj.38111.639734.7C.

Clarke A. (1999) Psychosocial aspects of facial disfigurement: problems, management and the role of a lay-led organization. Psychology, Health and Medicine 4, 127-142. doi:10.1080/ 135485099106270.

Cordova M.J., Giese-Davis J., Golant M., Kronenwetter C., Chang V. \& Spiegel D. (2007) Breast cancer as trauma: posttraumatic stress and posttraumatic growth. Journal of Clinical Psychology in Medical Settings 14, 308-319. doi:10.1007/s10880-007-9083-6.

Crocker J., Major B. \& Steele C. (1998) Social stigma. In: The Handbook of Social Psychology, 4th edn, Vol. 2 (eds Gilbert D.T., Fiske S.T. \& Lindzey G.), pp. 504 553. McGraw-Hill, Boston, MA, USA.
Denzin N.K. (1995) Symbolic interactionism. In: Rethinking Psychology (eds Smith J.A., Harre R. \& Van Langenhove L.), pp. 43-58. Sage, London, UK.

Devins G.M., Stam H. \& Koopmans J.P. (1994) Psychological impact of laryngectomy mediated by perceived stigma and illness intrusiveness. The Canadian Journal of Psychiatry 39, 608-616.

Dropkin M.J. (1989) Coping with disfigurement and dysfunction after head and neck cancer surgery: a conceptual framework. Seminars in Oncology Nursing 5, 213-219. doi:10.1016/0749-2081(89)90095-8.

Dropkin M.J. (1999) Body image and quality of life after head and neck cancer surgery. Cancer Practice 7, 309-313. doi:10.1046/j.1523-5394.1999. 76006.x.

Dropkin M.J. (2001) Anxiety, coping strategies, and coping behaviors in patients undergoing head and neck cancer surgery. Cancer Nursing 24, 143 148. doi:10.1097/00002820-20010400000010.

Dropkin M.J., Malgady R.G., Scott D.W., Oberst M.T. \& Strong E.W. (1983) Scaling of disfigurement and dysfunction in postoperative head and neck patients. Head and Neck Surgery 6, 559-570. doi:10.1002/hed.2890060104.

Fife B.L. \& Wright E.R. (2000) The dimensionality of stigma: a comparison of its impact on the self of persons with HIV/AIDS and cancer. Journal of Health 
and Social Behavior 41, 50-67. Joseph S. (2011) What Doesn't Kill Us: doi:10.2307/2676360.

Fingeret M.C., Yuan Y., Urbauer D., Weston J., Nipomnick S. \& Weber R. (2012) The nature and extent of body image concerns among surgically treated patients with head and neck cancer. Psycho-Oncology 21, 836-844. doi:10.1002/pon.1990.

Frampton M. (2001) Psychological distress in patients with head and neck cancer: review. British Journal of Oral and Maxillofacial Surgery 39, 1-4. doi:10.1054/bjom.2000.0547.

Gadamer H.-G. (1983) Hermeneutics as practical philosophy. In: Reason in the Age of Science (Transl. F. Lawrence), pp. 88-138. The MIT Press, Cambridge, UK.

Gamba A., Romano M., Grosso L.M., Tamburini M., Cantú G., Molinari R. \& Ventafridda V. (1992) Psychosocial adjustment of patients surgically treated for head and neck cancer. Head and Neck 14, 218-223. doi:10.1002/ hed.2880140309.

Goffman E. (1963) Stigma: Notes on the Management of Spoiled Identity. Prentice-Hall, Englewood Cliffs, NJ, USA.

Hagedoorn M. \& Molleman E. (2006) Facial disfigurement in patients with head and neck cancer: the role of social self-efficacy. Health Psychology 25, 643. doi:10.1037/0278-6133.25.5.643.

Hegel M.T., Collins E.D., Kearing S., Gillock K.L., Moore C.P. \& Ahles T.A. (2008) Sensitivity and specificity of the distress thermometer for depression in newly diagnosed breast cancer patients. Psycho-Oncology 17, 556-560. doi:10.1002/pon.1289.

Heidegger M. (1927/1962). Being and Time. Harper, New York, NY. (Original work published 1927).

Herrero R., Castellsagué X., Pawlita M., Lissowska J., Kee F., Balaram P., Rajkumar T., Sridhar H., Rose B., Pintos J., Fernández L., Idris A., Sánchez M.J., Nieto A., Talamini R., Tavani A., Bosch F.X., Reidel U., Snijders P.J.F., Meijer C.J.L.M., Viscidi R., Muñoz N. \& Franceschi S. (2003) Human papillomavirus and oral cancer: The International Agency for Research on Cancer multicenter study. Journal of the National Cancer Institute 95, 17721783. doi:10.1093/inci/dig107.

Holland J.C. \& Reznik I. (2005) Pathways for psychosocial care of cancer survivors. Cancer 104, 2624-2637. doi:10.1002/cncr.21252.

Jones E.E., Farina A., Hastorf A.H. \& deFrench R. S. (1984) Social Stigma: The Psychology of Marked Relationships. W.H. Freeman, New York, NY, USA
The New Psychology of Posttraumatic Growth. Basic Books, New York, NY, USA.

Joseph S. \& Linley P.A. (2005) Positive adjustment to threatening events: an organismic valuing theory of growth through adversity. Review of General Psychology 9, 262-280.

Joseph S., Maltby J., Wood A.M., Stockton H., Hunt N. \& Regel S. (2012) The Psychological Well-Being-PostTraumatic Changes Questionnaire (PWB-PTCQ): reliability and validity. Psychological Trauma: Theory, Research, Practice, and Policy 4, 420428. doi:10.1037/a0024740.

Koster M. \& Bergsma J. (1990) Problems and coping behaviour of facial cancer patients. Social Science and Medicine 30, 569-578. doi:10.1016/0277-9536(90) 90155-L.

Krouse J.H., Krouse H.J. \& Fabian R.L. (1989) Adaptation to surgery for head and neck cancer. The Laryngoscope 99, 789-794.

Kuo T.-T. \& Ma F.-C. (2002) Symptom distresses and coping strategies in patients with non-small cell lung cancer. Cancer Nursing 25, 309-317. doi:10.1097/00002820-200208000-00007.

Lebel S. \& Devins G.M. (2008) Stigma in cancer patients whose behavior may have contributed to their disease. Future Oncology 4, 717-733. doi:10.2217/ 14796694.4.5.717.

Lebel S., Castonguay M., Mackness G., Irish J., Bezjak A. \& Devins G.M. (2013a) The psychosocial impact of stigma in people with head and neck or lung cancer. Psycho-Oncology 22, 140152. doi:10.1002/pon. 2063.

Lebel S., Tomei C., Feldstain A., Beattie S. \& McCallum M. (2013b) Does fear of cancer recurrence predict cancer survivors' health care use? Supportive Care in Cancer 21, 901-906. doi: 10.1007/s00520-012-1685-3.

Livingston J.D. \& Boyd J.E. (2010) Correlates and consequences of internalized stigma for people living with mental illness: a systematic review and meta-analysis. Social Science and Medicine 71, 2150-2161. doi:10.1016/ j.socscimed.2010.09.030.

Llewellyn C.D., Horney D.J., McGurk M., Weinman J., Herold J., Altman K. \& Smith H.E. (2013) Assessing the psychological predictors of benefit finding in patients with head and neck cancer. Psycho-Oncology 22, 97-105. doi:10.1002/pon.2065.

Macgregor F.C. (1990) Facial disfigurement: problems and management of social interaction and implications for mental health.
Aesthetic Plastic Surgery 14, 249-257. doi:10.1007/BF01578358.

McCormack L. \& Joseph S. (2013) Psychological growth in humanitarian aid personnel: reintegrating with family and community following exposure to war and genocide. Community, Work and Family 16, 147-163. doi:10.1080/ 13668803.2012.735478.

McCormack L. \& Joseph S. (2014) Psychological growth in aging vietnam veterans redefining shame and betrayal. Journal of Humanistic Psychology 54, 336-355. doi:10.1177/0022167813501393.

McCormack L., Hagger M.S. \& Joseph S. (2011) Vicarious growth in wives of Vietnam veterans: a phenomenological investigation into decades of "lived" experience. Journal of Humanistic Psychology 51, 273-290. doi:10.1177/ 0022167810377506.

Morrill E.F., Brewer N.T., O'Neill S.C., Lillie S.E., Dees E.C., Carey L.A. \& Rimer B.K. (2008) The interaction of post-traumatic growth and posttraumatic stress symptoms in predicting depressive symptoms and quality of life. Psycho-Oncology 17, 948-953. doi:10.1002/pon.1313.

Myers E.N., De Boer M.F., McCormick L.K., Pryun J.F., Ryckman R.M. \& van den Borne B. (1999) Physical and psychosocial correlates of head and neck cancer: a review of the literature. Otolaryngology-Head and Neck Surgery 120, 427-436.

Nolen-Hoeksema S. \& Davis C.G. (2004) Theoretical and methodological issues in the assessment and interpretation of posttraumatic growth. Psychological Inquiry 15, 60-64.

Peters-Golden H. (1982) Breast cancer: varied perceptions of social support in the illness experience. Social Science and Medicine 16, 483-491. doi:10.1016/ 0277-9536/82/90057-0.

Raleigh Z.T. (2010) A biopsychosocial perspective on the experience of lung cancer. Journal of Psychosocial Oncology 28, 116-125. doi:10.1080/ 07347330903438990.

Ruf M., Büchi S., Moergeli H., Zwahlen R.A. \& Jenewein J. (2009) Positive personal changes in the aftermath of head and neck cancer diagnosis: a qualitative study in patients and their spouses. Head and Neck 31, 513-520. doi:10.1002/hed.21000.

Ryff C.D. (1989) Happiness is everything, or is it? Explorations on the meaning of psychological well-being. Journal of Personality and Social Psychology 57, 1069-1081. 3514.57.6.1069.

Silver R.L. \& Wortman C.B. (1980) Coping with undesirable life events. In: Human 
Helplessness: Theory and Applications (eds Garber J. \& Seligman M.E.P.), pp. 297-340. Academic Press, New York, NY, USA.

Smith J.A. (1996) Beyond the divide between cognition and discourse: using interpretative phenomenological analysis in health psychology. Psychology and Health 11, 261-271. doi:10.1080/08870449608400256.

Smith J.A. \& Osborn M. (2008) Interpretative phenomenological analysis. In: Qualitative Psychology: A Practical Guide to Research Methods (ed. Smith J.A.), pp. 53-80. Sage, London, UK.

Smith J.A., Michie S., Stephenson M. \& Quarrell O. (2002) Risk perception and decision-making processes in candidates for genetic testing for Huntington's disease: an interpretative phenomenological analysis. Journal of Health Psychology 7, 131-144. doi:10.1177/1359105302007002398.

Smith J.A., Flowers P. \& Larkin M. (2009) Interpretative Phenomenological Analysis: Theory, Method and Research. Sage, London, UK.
Spinelli E. (2005) The Interpreted World: An Introduction to Phenomenological Psychology, 2nd edn. Sage, London, UK.

Stanton A.L. (2006) Psychosocial concerns and interventions for cancer survivors. Journal of Clinical Oncology 24, 51325137. doi:10.1200/JCO.2006.06.8775.

Suls J. (1982) Social support, interpersonal relations, and health: benefits and liabilities. In: Social Psychology of Health and Illness (eds Sanders G. \& Suls J.), pp. 255-277. Erlbaum, Hillsdale, NJ, USA.

Tedeschi R.G. \& Calhoun L.G. (1995) Trauma and Transformation: Growing in the Aftermath of Suffering. Sage Publications, Thousand Oaks, CA, USA. Thambyrajah C., Herold J., Altman K. \& Llewellyn C. (2010) "Cancer doesn't mean curtains": benefit finding in patients with head and neck cancer in remission. Journal of Psychosocial Oncology 28, 666-682. doi:10.1080/ 07347332.2010 .516812$.

Tod A.M., Craven J. \& Allmark P. (2008) Diagnostic delay in lung cancer: a qualitative study. Journal of Advanced
Nursing 61, 336-343. doi:10.1111/j.13652648.2007.04542.x.

Turpin M., Dallos R., Owen R. \& Thomas M. (2009) The meaning and impact of head and neck cancer: an interpretative phenomenological and repertory grid analysis. Journal of Constructivist Psychology 22, 24-54. doi:10.1080/ 10720530802500789.

Weiss T. (2004) Correlates of posttraumatic growth in married breast cancer survivors. Journal of Social and Clinical Psychology 23, 733-746. doi:10.1521/jscp.23.5.733.50750.

Widows M.R., Jacobsen P.B. \& Fields K.K. (2000) Relation of psychological vulnerability factors to posttraumatic stress disorder symptomatology in bone marrow transplant recipients. Psychosomatic Medicine 62, 873-882. doi:10.1097/00006842-200011000-00018.

Zabora J., Brintzenhofeszoc K., Curbow B., Hooker C. \& Piantadosi S. (2001) The prevalence of psychological distress by cancer site. Psycho-Oncology 10, 19-28. doi:10.1002/1099-1611(200101/02)10:1<19: AID-PON501>3.0.CO;2-6. 